\title{
Development of Test Method for Evaluating Root Resistance Using Simulated Root focus on the Enlargement Growth of Root
}

\author{
Saori Ishihara* and Kyoji Tanaka
}

Structural Engineering Research Center, Tokyo Institute of Technology, 4259 Nagatsuta, Midori-ku, Yokohama, Japan

\begin{abstract}
Damages such as rising and cracking due to enlargement growth of roots are quite often observed in the components such as path pavements, curbs, retaining walls and garden furniture on green roof. To avoid the defects, root resistance of those components used for green roof should be estimated by a suitable test before actual applications of them. In this study a test apparatus and a test method to evaluate root resistance caused by enlargement growth of root were developed.

First, the simulated root for similarly reproducing the enlargement growth was developed on the basis of the actual behavior of the root of a cherry tree. It consists of two half cylinders of aluminum and a hydraulic jack inserted between them, and the whole simulated root covered with EVA sheet to give the similar mechanical property of the root.

Then, the root resistance test was carried out using the simulated root for an asphaltic pavement as an example. It was observed that the test result of nature of asphaltic pavement damage was similar to that observed on actual asphaltic pavements. It was found that the simulated root was useful for evaluating root resistance.
\end{abstract}

Keywords: Green Roof, Root Resistance, Woody Plants, Enlargement Growth, Asphaltic Pavement.

\section{INTRODUCTION}

Tree planting around buildings has gained popularity. Trees are usually planted outside buildings, on building rooftops, or on the walls of buildings. Normally, these trees are planted close to components such as curbstones, asphaltic pavements, brick sidewalks, retaining walls, or other garden furniture and building materials. However, the roots of these trees may cause damage to the adjacent materials. The damages may divide two types, one is caused by elongation growth of root and the other is by enlargement growth of root. Fig. (1) shows examples of damages caused by enlargement growth of root. Some asphaltic pavement surface on the sidewalk may be lifted by the enlargement of the roots and may crack along the roots; similarly, in the case of brick sidewalks, the bricks may be lifted or damaged by roots. The research about damages of pavement due to enlargement growth of root has been studied [1, 2]. In green roof, the soil thickness is the absolute minimum required for plant growth, and soil thicknesses are thin to minimize the weight of the planting. Therefore, enlargement of plant roots directly affects the materials adjacent to the roots. This is a serious defect that not only hindrance to walking but also reduces the esthetic value of these sites.

To avoid these defects, the suitability of using these materials around plants should be evaluated beforehand. In regard to past studies on this subject, test method for evaluate root resistance have been standardized such as DIN 4062 [3], the test method by FLL [4] (the Landscaping and Landscape Development Research Society e.v.), Japanese Architectural

Address correspondence to this author at the Structural Engineering Research Center, Tokyo Institute of Technology, 4259 Nagatsuta, Midori-ku, Yokohama, Japan; Tel: +81-45-924-5329; Fax: +81-45-924-5339;

E-mails: saori@serc.titech.ac.jp; lainass@proof.ocn.ne.jp
Standard Specifications JASS8 T-401 [5], in which actual plants are planted in containers applied test specimen inside. These tests are only for waterproofing membrane. Although such evaluations can be performed using actual plants, they would involve very large-scale experiments, and the results of these experiments can be obtained only after a long time. Most importantly, these results may also be affected by the plant growth conditions. To ensure rapid results and simplify evaluation, simulated roots, which simulate the behavior of actual roots, should be used.

Based on that background, the purpose of this study is to develop the test method for evaluating root resistance speedy and easy than the test using actual plants, and remove the affect of individual difference of actual plant. We develop the test method using the simulated root as a way to that purpose.

We first used Prunus yedoensis (Japanese cherry tree), which is often planted on the roadside, in the green areas of parks, and on green roof, and studied the root behavior to determine the magnitude of the force generated during growth of roots. Using this information, we aimed to develop a simulated root that could be used to evaluate the root resistance of materials around planted areas and examined the usefulness of this simulated root in root resistance evaluation test.

\section{MEASURING THE ENLARGEMENT FORCE EX- ERTED BY ROOT GROWTH}

\subsection{A System to Measure the Enlargement Force Exerted by Root Growth}

The research about enlargement growth of root has been studied [6,7] but, nobody measured the enlargement 

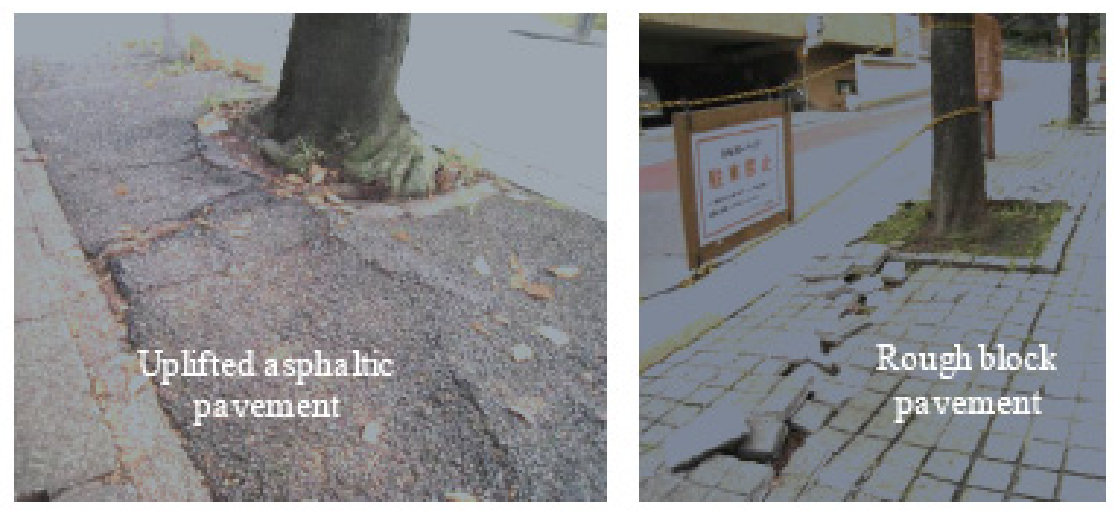

Fig. (1). Damages caused by the enlargement of the roots.

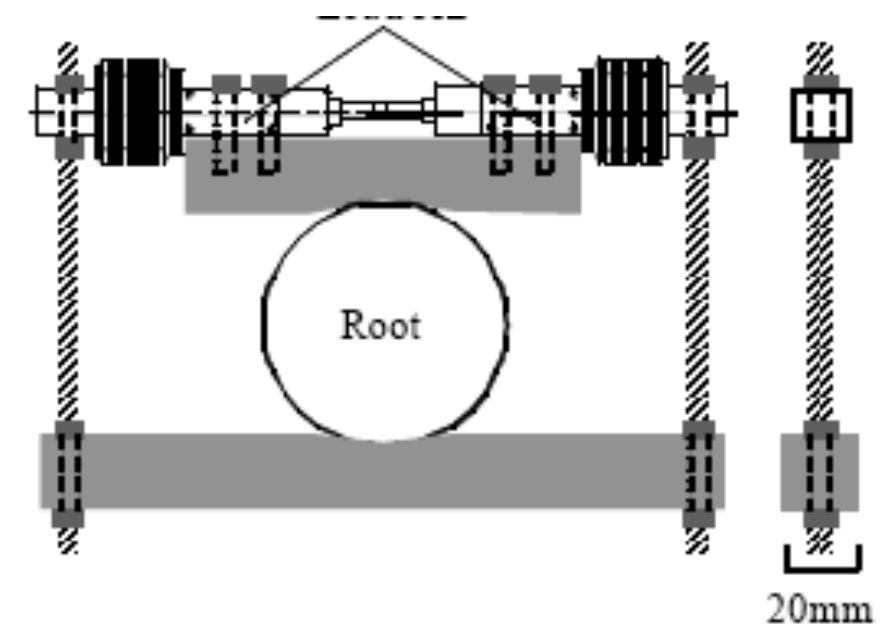

Fig. (2). A system to measure the enlargement force of root.

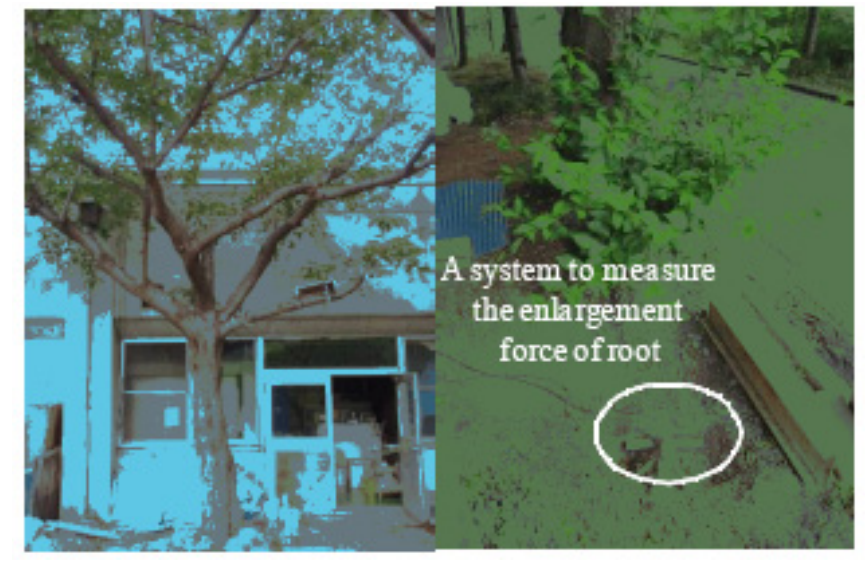

Fig. (3). Cherry tree using measurement and measuring situation of enlargement force of root.

growth of root. Therefore first we measured the enlargement force.

The roots grow around the radical axis. However, defects in the materials around the planted areas are often caused by root enlargement in the diametrical direction. Therefore, we developed a system to measure the enlargement force exerted by root growth in the diametrical direction. An outline of the measurement system is shown in Fig. (2). The root was firmly held with aluminum square bars above and below it, and the enlargement force exerted against the aluminum square bars by the growing root was measured using load cells attached symmetrically on the top of the root. The square bars and load cells were fixed with bolts to ensure that the root growth is measured under constrained conditions.

\subsection{Measurement Procedures}

We used a cherry tree (age, approximately 21 years; circumference at breast height, $138 \mathrm{~cm}$ ) for the initial measurements. We dug the ground and attached the measuring 
system at a position approximately $2 \mathrm{~m}$ away from the tree. Since the root surface is uneven, we filled epoxy resin in the gaps between the aluminum bars of the system and the root to ensure adherence between the system and the plant root. Fig. (3) shows the cherry tree used in the measurement and the conditions under which the measurement system was installed. While roots were not covered by soil during this measurement, we ensured that the conditions were similar to those under the soil by winding many layers of wetted paper around the roots to avoid excessive drying of the exposed sections. Furthermore, to avert the effects of direct sunlight, rain, and wind and to protect the roots, a metal plate cover was attached on top of the system. Measurements were obtained from March through early August of 2009, when root enlargement is assumed to occur.

\subsection{Measurement Results}

The measurement results are shown in Fig. (4). Although increase in load was not observed in March, from April, the load increased gradually over repeating cycles (decrease from dawn to daytime and increase from daytime to midnight by day) caused by transpiration; then, from the middle of May, the load increased rapidly until it slowed down in late July. The maximum value was obtained on July 29, 2009 , when the force exerted by root enlargement was 440 $\mathrm{N} / \mathrm{cm}$. Since then, this force tended to level off; therefore, measurement was ended on August 2.

\section{MEASUREMENT OF ROOT SHAPES AND ME- CHANICAL PROPERTIES}

\subsection{Root Shape}

To prepare simulated roots for root resistance evaluation test, we required information on the actual root shape and its mechanical properties. Therefore, we studied the shapes and mechanical properties of the roots of cherry tree, which was used to measure the enlargement force exerted by root growth. Fig. (5) shows the sketch of the root system and its vertical and lateral diameters. The root cross section is basically a circle or portrait oval. Several thick prop roots extend horizontally from the trunk, and small roots branch out of these prop roots. Furthermore, lateral roots grow out of the

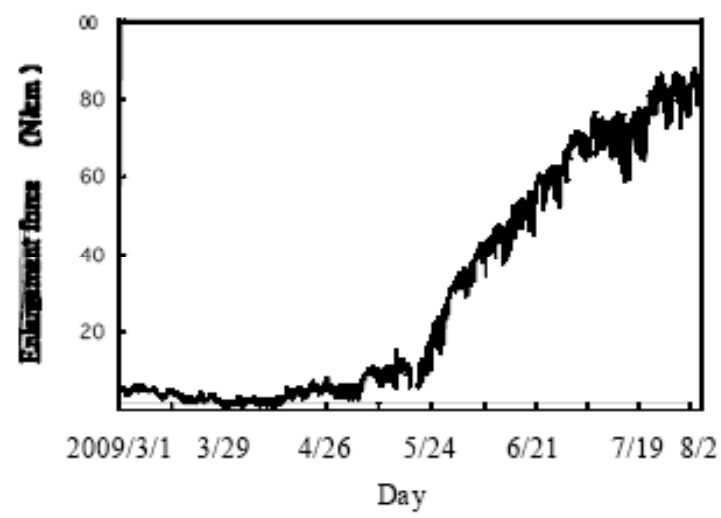

Fig. (4). Variations in enlargement force of root of cherry blossom.

middle of the prop roots. Among these, the parts that cause defects such as hinder walking or spoil the appearance are the roots within a few meters from the trunk. The diameters of these parts ranged from $10 \mathrm{~cm}$ to several centimeters.

\subsection{Root Cross Section and Mechanical Properties}

Roots were cut out from several sections to measure their mechanical properties in compression tests. A total of 5 root specimens with diameter of approximately $100 \mathrm{~mm}$ and lengths of $3 \mathrm{~cm}$ were obtained, and they were compressed at the rate of $1 \mathrm{~mm} / \mathrm{min}$ to study the relationship between load and displacement. The measurement conditions are shown in Fig. (6), and the results are shown in Fig. (7). The load constantly increased with an increase in compression. Since we did not require data for fairly large displacements to develop the simulated roots, we terminated measurements at a displacement of $2 \mathrm{~mm}$.

\section{PREPARATION OF SIMULATED ROOTS}

\subsection{Basic Concept of Simulated Roots}

Since the actual root growth occurs in the circumferential direction, the force applied by roots would be theoretically caused by enlargement of the entire root. However, as shown in Fig. (1), most of the damage is caused by an upward force,

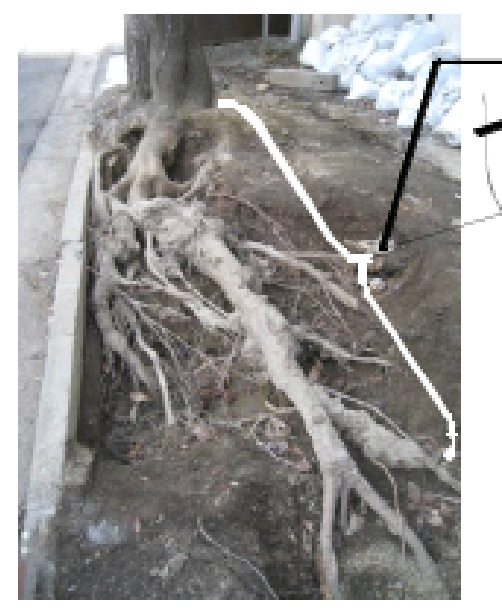

Observed this area
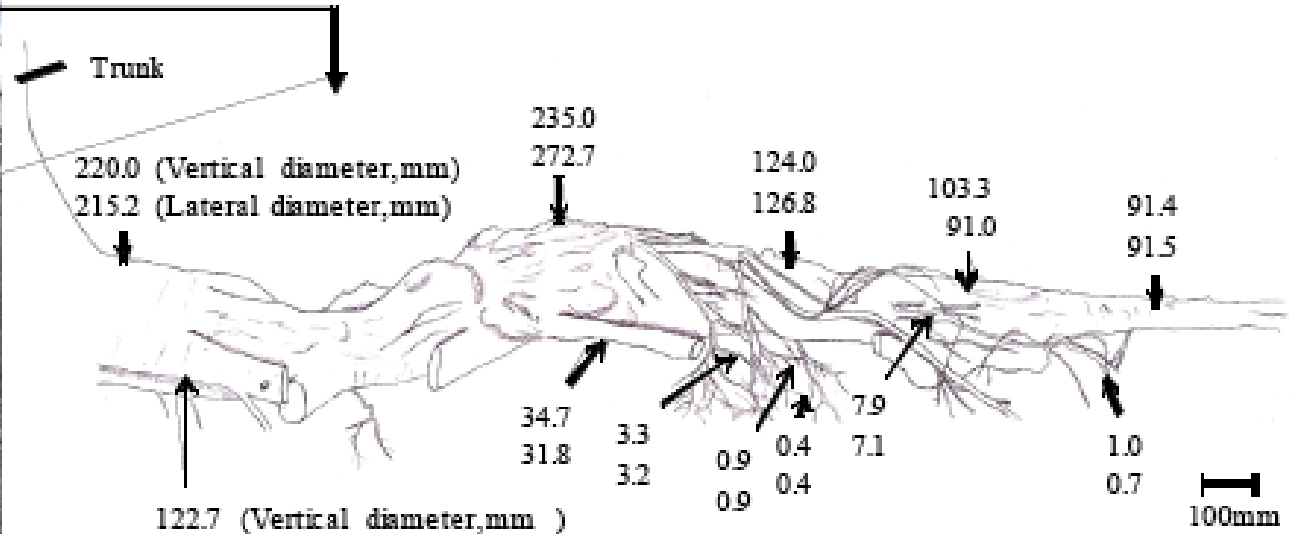

1118 (Lateral diameter, $\mathrm{mm}$ )

Fig. (5). Shapes of roots of cherry tree (vertical diameter, lateral diameter). 
and therefore, root resistance can be evaluated simply by exerting an upward compressive force. Owing to the simplicity of this approach, we decided to adopt a root simulation mechanism for uniaxial compression.

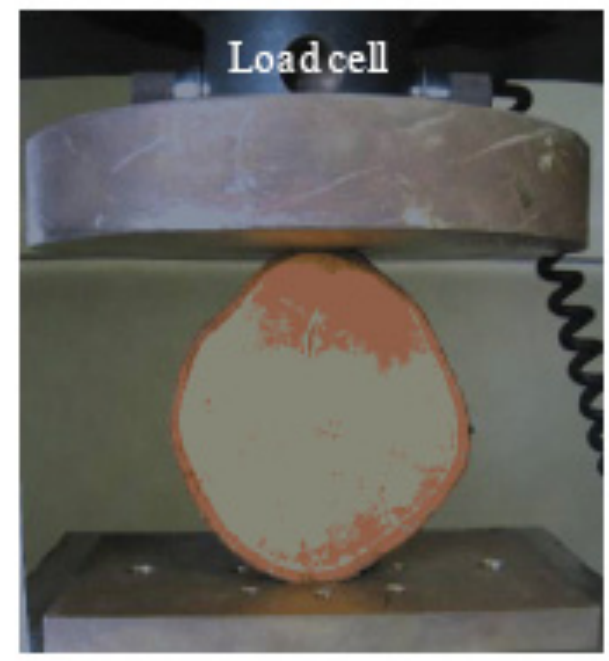

Fig. (6). Situation for compression test of cross-section of cherry tree $\left(1 \mathrm{~mm} / \mathrm{min}, 20^{\circ} \mathrm{C}\right)$.

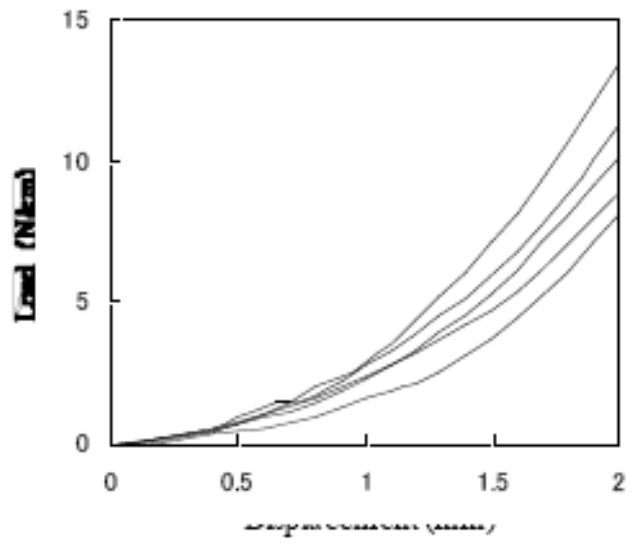

Fig. (7). Relationship between load and displacement measured by compression test of root of cherry tree.

\subsection{Mechanism and Construction of the Simulated Roots}

As shown in Fig. (8), enlargement of a root was simulated by pushing up the upper and lower semicircular aluminum columns, which simulated the cross section of a root, by using a small hydraulic jack. The hydraulic jack had a maximum stroke of $10 \mathrm{~mm}$; therefore, the simulated root could be enlarged up to $10 \mathrm{~mm}$. Load cells were attached inside the simulated root, thereby allowing measurement of the pressure generated by the simulated root during the test. The root thickness was set to $10 \mathrm{~cm}$, which was considered as the representative size of the cherry root sections tree that caused most damage. The length of the simulated root was also set to $10 \mathrm{~cm}$.

However, the aluminum is too hard compared to cherry root. To be brought close to the mechanical properties of the cherry tree, we attempted to simulate the mechanical properties of actual roots by covering the surface of the aluminum columns with an elastic material.
To select the ideal surface material, the aluminum columns with various elastic sheets were carried out the compression test at a rate of $1 \mathrm{~mm} / \mathrm{min}$, similar to the compression test performed in section 3.2, and studied the relationship between load and displacement in these structures by compressing them (length of the block used for the measurement, $3 \mathrm{~cm}$ ). The elastic sheets used in this investigation are listed in Table $\mathbf{1 .}$

The measurement results are shown in Fig. (9). With an increase in displacement, the load tended to increase in the order sponge sheet $<$ EVA sheet $<$ cork sheet $<$ rubber sheet $<$ EPDM reinforced sheet. The behavior under compression of EVA sheet $(2 \mathrm{~mm})$ was similar to the actual root behavior shown in Fig. (7). Therefore, we adopted a simulated root by covering the aluminum semicircular columns with EVA sheets $(2 \mathrm{~mm})$. The simulated root and the compression system are shown in Fig. (10).

\subsection{Assessment of Reproduction of the Root-Growth Force by the Simulated Root}

To determine whether our simulated roots could apply the load obtained in the trials with cherry roots $(440 \mathrm{~N} / \mathrm{cm})$, we inserted the simulated root into the system used for measuring the enlargement force exerted by root growth. Simulated root was fixed at the top and bottom with the system which used for measuring the enlargement force of cherry tree, and apply the pressure to simulated root by hydraulic jac $\mathrm{k}$, then measured the load on the simulated root and the load obtained by the system, as shown in Fig. (11). Pressurization of the simulated root was terminated when its load exceeded $440 \mathrm{~N} / \mathrm{cm}$.

The measurement results in Fig. (12) indicate that the simulated root was capable of applying a load of $440 \mathrm{~N} / \mathrm{cm}$, which was equal to the maximum force exerted by enlargement of cherry roots.

\section{EVALUATION OF THE ROOT RESISTANCE OF ASPHALTIC PAVEMENT SPECIMENS BY USING SIMULATED ROOTS}

\subsection{Specimen}

We studied the usefulness of the simulated roots in root resistance evaluation test by performing trials using asphaltic pavement specimens obtained from a sidewalk. Asphaltic pavements show a wide range of variations ranging from

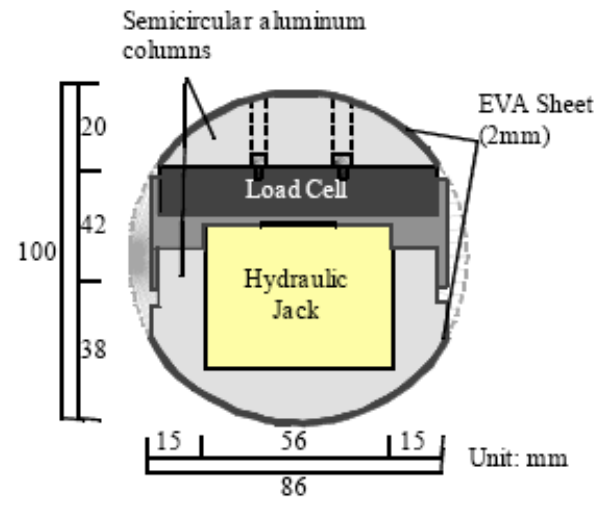

Fig. (8). Cross-section of simulated root. 
Table 1. Observed Sheet to Select Surface Material of Simulated Root

\begin{tabular}{l|c|c}
\hline \multicolumn{1}{c|}{ Material } & Thickness & Hardness \\
\hline Cork sheet & $2 \mathrm{~mm}$ & 51.5 \\
Rubber sheet & $3 \mathrm{~mm}$ & 63.2 \\
\hline EVA sheet & $2 \mathrm{~mm}$ & 27.2 \\
(ethylene-vinyl acetate) & $3 \mathrm{~mm}$ & 28.3 \\
& $5 \mathrm{~mm}$ & 29.4 \\
\hline Sponge sheet & $5 \mathrm{~mm}$ & 7.4 \\
EPDM reinforced sheet & $1.5 \mathrm{~mm}$ & 66.1 \\
\hline
\end{tabular}

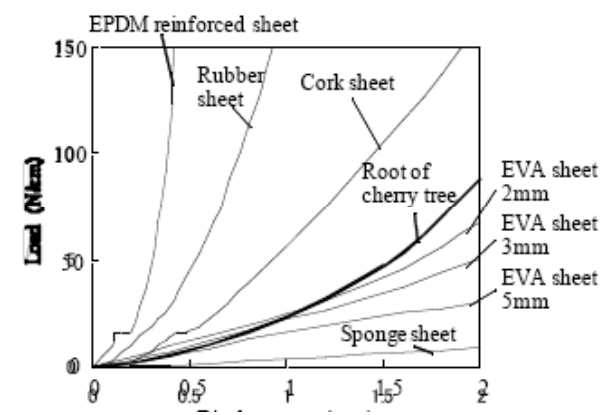

Fig. (9). Relationship between displacement and load measured by compression test of simulated root covered with various surface materials $\left(1 \mathrm{~mm} / \mathrm{min}, 20^{\circ} \mathrm{C}\right)$.

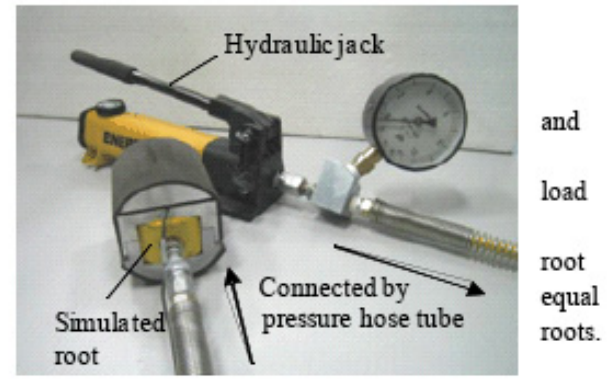

Fig. (10). Simulated root and hydraulic jack for pressurization.

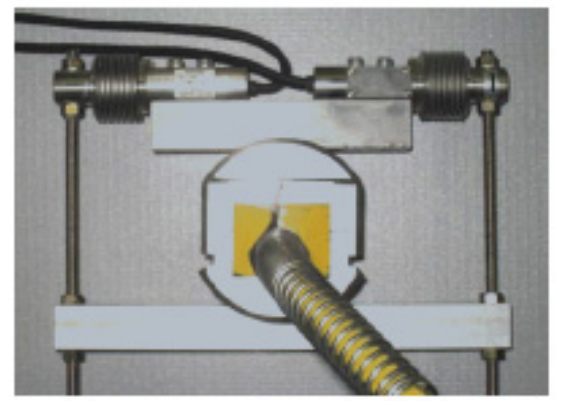

Fig. (11). Situation of measuring for pressurization of simulated root

full-fledged pavements with a sufficiently thick layer of roadbed materials such as crushed stones, gravel, and slugs to simple pavements with a layer of sand as the roadbed material. In this study, we used a relatively simple type of pavement, which is shown in Fig. (13), to confirm the usefulness of the simulated roots. This pavement specimen comprised a layer of sand leveled out over the slab as the roadbed material and asphalt applied over it. The thickness of the roadbed material above the root is believed to influence the magnitude of defects such as cracking and lifting of the asphaltic pavement. Therefore, we prepared specimens with 4 levels of bed thickness above the simulated root $(0$ $\mathrm{mm}, 10 \mathrm{~mm}, 20 \mathrm{~mm}$, and $50 \mathrm{~mm}$ ).

Further, asphaltic pavements usually show some flexibility after construction; therefore, many kinds of damage cannot be observed immediately after construction, and these are observed only after the pavement has undergone some deterioration over time. Ther efore, we performed tests with an asphaltic pavement that was used on an actual sidewalk for about 10 years. Relationship between load and displacement of the asphalt measured by three-point bending test was shown as Fig. (14). The young modulus calculated by the results of three-point bending test was $2.1 \times 10^{8} \mathrm{~N} / \mathrm{cm}^{2}$. To obtain specimens from this pavement, we cut out parts with length, width, and thickness of $680 \mathrm{~mm}, 100 \mathrm{~mm}$, and 30 $\mathrm{mm}$, respectively, by using a concrete cutter.

\subsection{Test Method}

This test was conducted by using the simulated root to apply the pressure exerted by root enlargement on an asphaltic pavement specimen fixed with supporting points at 600 $\mathrm{mm}$ intervals and studying the deformation and damage in

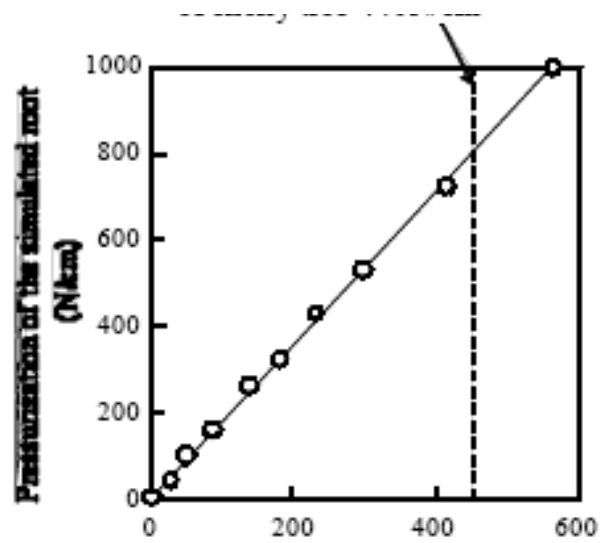

Fig. (12). Relationship between load measured by system which measure the enlargement force of root and pressurization of simulated root.

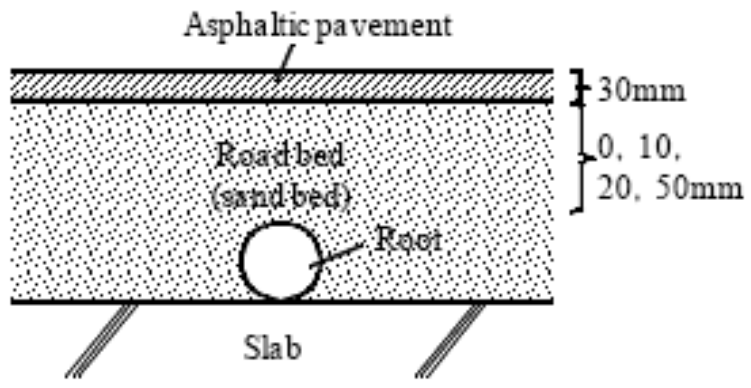

Fig. (13). Cross-section of asphaltic pavement. 


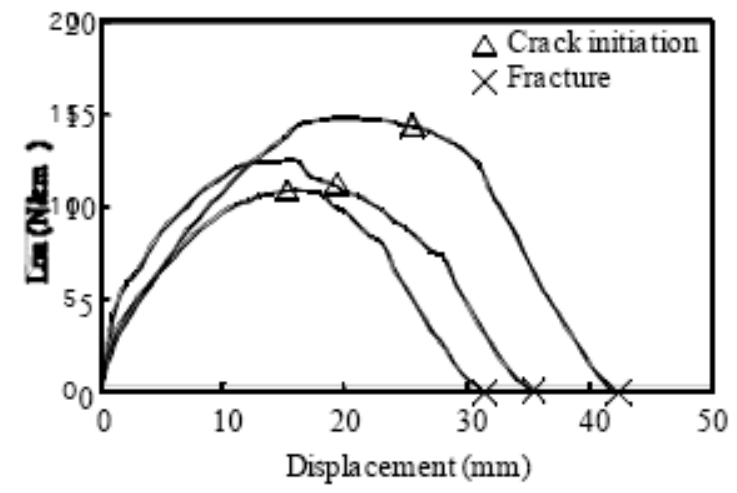

Fig. (14). Relationship between load and displacement measured by three-point bending test of asphaltic pavement.

the specimen after pressurization.

The testing system for this trial included a container with inner length, width, and height of $700 \mathrm{~mm}, 110 \mathrm{~mm}$, and 330 $\mathrm{mm}$, which could contain the previously described asphaltic pavement, and the simulated root was set up at the center below the specimen. The asphaltic pavement was fixed with support rods to prevent its ends from moving, and then the pavement was lifted up by pressurization of the roadbed by the simulated root.

The following test procedures were employed: First, the simulated root was installed in the container. Then, sand was filled as the roadbed layer to the specified thickness with

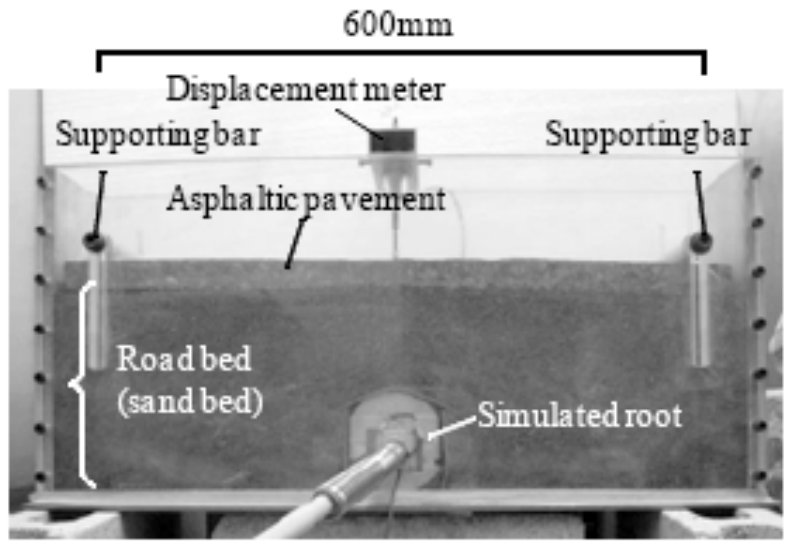

Fig. (15). Root resistance test.

sufficiently tight packing. The asphaltic pavement was then laid, and both edges were fixed with the supporting bars. Next, oil was transferred to the simulated root from the hydraulic jack to pressurize the roadbed and asphaltic pavement from underneath. In our previous trial using cherry roots (section 2.3), the enlargement force exerted by root growth increased to $440 \mathrm{~N} / \mathrm{cm}$ with a very slow average increase rate of $5 \mathrm{~N} / \mathrm{cm}$ per day in 3 months from May to July, as shown in Fig. (4). However, in our indoor test, we manually exerted pressure on the pavement with a target pressurization rate of $5 \mathrm{~N} / \mathrm{cm}$ per minute to obtain results in a short period.

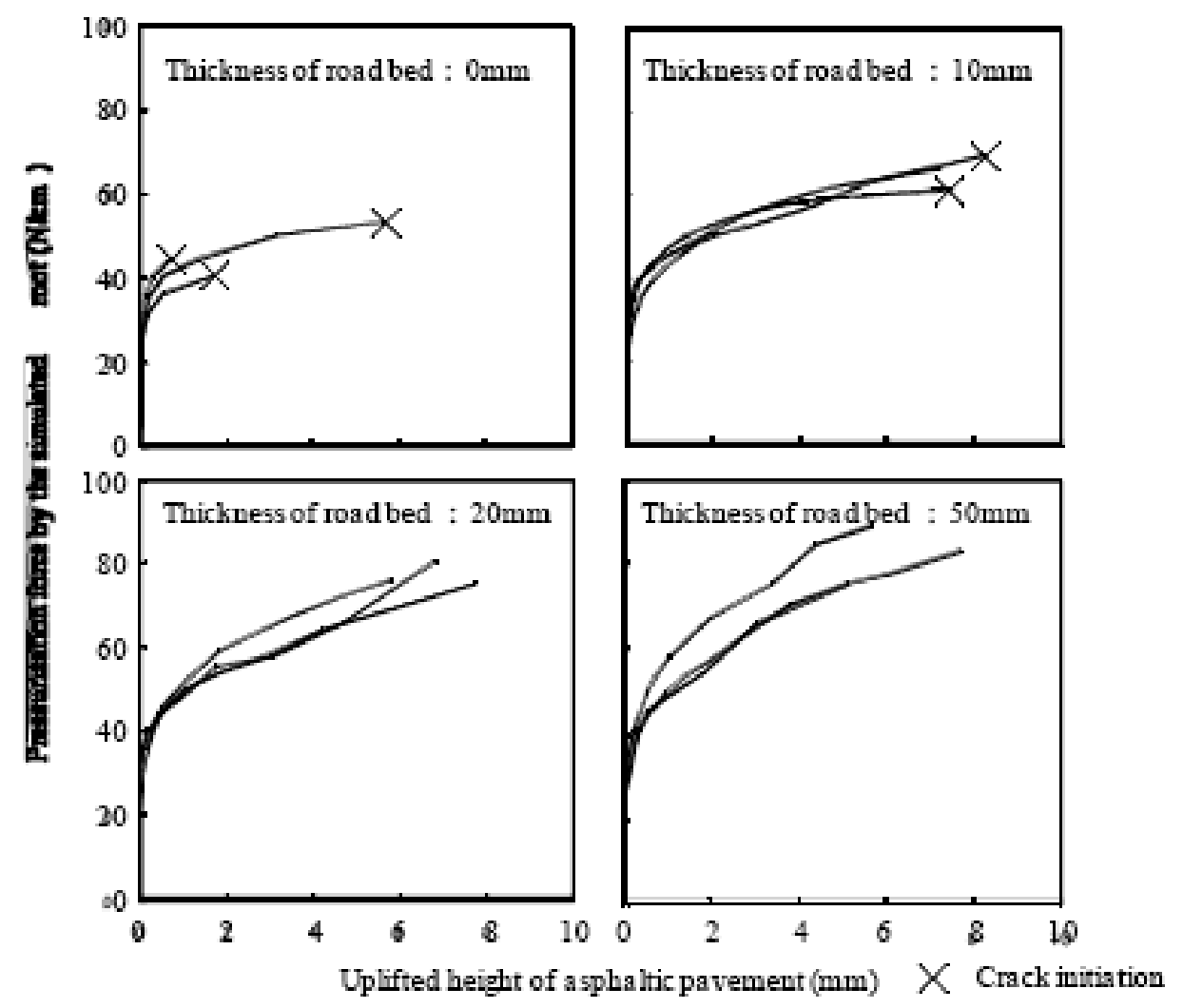

Fig. (16). Relationship between pressurization force by the simulated root and uplifted height of asphaltic pavement with various thickness of top of the simulated root to asphaltic pavement. 


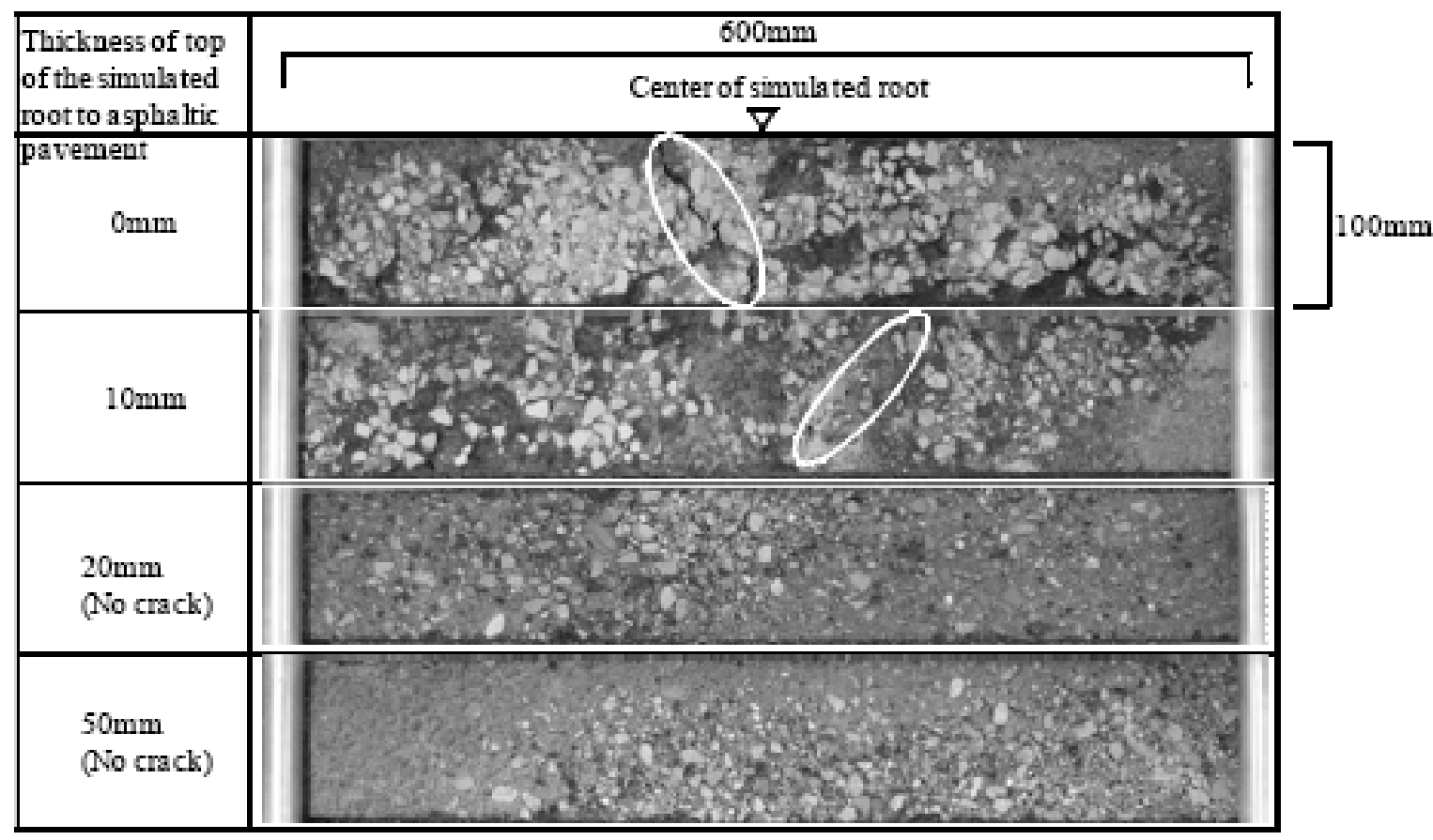

Fig. (17). Cracks occurred surface of asphaltic pavement.

The test conditions are shown in Fig. (15). We visually monitored the cracks on the asphaltic pavement surface. The height to which the asphaltic pavement center was lifted was also measured using a displacement meter. The test was considered complete when cracks were generated on the asphaltic pavement or when the maximum deformation $(10 \mathrm{~mm})$ of the simulated root was achieved.

\subsection{Results and Discussion}

Fig. (16) indicates the height to which the asphaltic pavement surface was lifted when the simulated root was pressurized. An increase in the pressurization force by the simulated root caused a gradual elevation in the asphaltic pavement surface. Cracks were generated on the asphalt surface when the roadbed thickness above the simulated root was $0 \mathrm{~mm}$, or $10 \mathrm{~mm}$. The pressurization force at which cracking occurred was about $60 \mathrm{~N} / \mathrm{cm}$ when the roadbed thickness was $10 \mathrm{~mm}$, while it was $45 \mathrm{~N} / \mathrm{cm}$ when the roadbed thickness was $0 \mathrm{~mm}$. The conditions under which cracks formed on the asphaltic pavement surface are shown in Fig. (17). Irrespective of the roadbed thickness, cracking usually occurred at points directly above the center of the simulated root.

In addition, we observed that the height to which the pavement was lifted tended to decrease as the thickness of the roadbed increased. We surmise that this is because the roadbed layer acts as a buffer layer and disperses the force from the simulated root; conversely, in the case of thin pavements, the force from the simulated root is applied directly on the asphaltic pavement. In either case, the distance between the asphalt and the root was considered to be an important factor in determining the damage to the asphaltic pavement.

The nature of this damage was similar to that observed on actual asphaltic pavements on a sidewalk, and we as- sumed that the simulated root developed in this study will be useful for evaluation of root resistance test.

\section{CONCLUSION}

In this research simulated root was developed and make it possible to evaluate root resistance speedy and easy than the test using actual plants.

First we developed a system to measure the enlargement force exerted by roots growth and measured this force. We used this system to measure the force of cherry root and determined that the maximum force exerted by root enlargement between mid-April and late July was approximately $440 \mathrm{~N} / \mathrm{cm}$.

Then we developed a simulated root. It consists of semicircular aluminum columns, a hydraulic jack, a load cell and EVA sheet $(2 \mathrm{~mm})$ based on the measurement of root shapes and mechanically properties of cherry root. We confirmed that a load of $440 \mathrm{~N} / \mathrm{cm}$ could be actually exerted by simulated root.

Finally we conducted a root resistance test on a simple asphaltic pavement as an example. It was assumed that the simulated root developed in our study was useful for evaluate of root resistance.

\section{REFERENCES}

[1] H. Okawa, and S. Kurihara, "Damages of sidewalk pavement due to plant", Pavement(Japanese), vol. 42, no. 7, pp. 21-24, July 2007.

[2] A. Iwata, Y. Kida, T. Kouno, and N. Karizumi, "Study on the influence on the road structures by the root growth of Japanese zelkova street trees", Journal of the Japanese Institute of Landscape Architecture (Japanese), vol. 59, pp. 49-52, March 1996.

[3] DIN 4062, "Testing the Weed Resistance of Everlast-Roofskin".

[4] P. Fischer, R. Bohlen, R. Klein, J. Lieseche, G. Losken, P. Siegert, W. Tebart, and R. Walter, "Procedure for investigation resistance to root penetration at green-roof sites", The Landscaping and Landscape Development Research Society e.v.(FLL), 2002. 
[5] Architectural Institute of Japan, Japanese Architectural Standard Specifications, Japan: "T-401 Test Method of Evaluating Root Resistance for Waterproofing Membrane System for Green Roof", 2008.

[6] M.G. Huck, B. Klepper, and H. M. Taylor, "Diurnal variations in root diameter”, Plant Physiology, vol. 45, pp. 529-530, April 1970.
[7] M. Genard, S. Fishman, G. Vercambre, J-G. Huguet, C. Bussi, J. Besset, and R. Habib, "A biophysical analysis of stem and root diameter variations in woody plants", Plant Physiology, vol. 126, pp. 188-202, May 2001.

(C) Ishihara and Tanaka; Licensee Bentham Open.

This is an open access article licensed under the terms of the Creative Commons Attribution Non-Commercial License (http://creativecommons.org/licenses/by-nc/3.0/) which permits unrestricted, non-commercial use, distribution and reproduction in any medium, provided the work is properly cited. 